\title{
Thyroid Function in Children with Down Syndrome in the Polish Population: A Case-Control Study
}

\author{
Beata Zelazowska-Rutkowska, MD'1; Anna Jakubiuk-Tomaszuk, $\mathrm{MD}^{2}$; Bogdan Cylwik, $\mathrm{PhD}^{{ }^{*}}$ \\ 'Department of Paediatric Laboratory Diagnostics, Medical University of Bialystok, Bialystok, Poland \\ ${ }^{2}$ Department of Pediatric Neurology, Medical University of Bialystok, Bialystok, Poland
}

\begin{abstract}
Background: Patients with subclinical thyroid disease have few or no clinical symptoms of thyroid dysfunction and thus, laboratory diagnosis is needed. In this context, the objective of the current study was to analyze the prevalence rate and pattern of thyroid function in children with Down syndrome in the Polish population.

Methods: A total of 30 children, aged 6-12 years, with cytogenetically confirmed Down syndrome were studied. The control group included 27 children.

Results: Of the 30 patients with Down syndrome, 14 (46.7\%) had abnormal thyroid profiles. Mean thyroid-stimulating hormone (TSH) and fT4 concentrations in children with Down syndrome were found to be significantly increased compared with the controls $(4.30 \pm 1.9 \mu \mathrm{lU} / \mathrm{mL}, 95 \% \mathrm{Cl}: 3.55-5.04 \mu \mathrm{lU} / \mathrm{mL}$ vs. $3.10 \pm 1.47 \mu \mathrm{lU} / \mathrm{mL}, 95 \%$ Cl: $2.52-3.68 \mu \mathrm{lU} / \mathrm{mL}, P=0.013,95 \%$ Cl: $0.26-2.14$, and $1.33 \pm 0.23 \mathrm{ng} / \mathrm{dL}, 95 \% \mathrm{Cl}: 1.25-1.42$ vs. $1.19 \pm 0.14 \mathrm{ng} / \mathrm{dL}, 95 \% \mathrm{Cl}: 1.13-1.25, P=0.008,95 \% \mathrm{Cl}: 0.04-0.24$, respectively). In Down syndrome, subclinical hypothyroidism was recognized in 10 children (33.3\%) (high TSH and normal fT4 and fT3 levels). Two children (6.67\%) had evident hypothyroidism (high TSH and low fT4). In the control group, subclinical hypothyroidism was diagnosed in four $(14.8 \%)$ children.

Conclusion: Children with Down syndrome may have increased secretion of TSH, even when thyroid hormone and autoantibodies are normal, suggesting that an isolated increase in TSH does not predispose the patient to the development of thyroid disease. We also recommend that all patients with Down syndrome should be screened for thyroid dysgenesis, since they have thyroid dysfunction more frequently as compared to the general healthy population.

Keywords: Antibodies, Down syndrome, Thyroid function tests, Thyroid hormones

Cite this article as: Zelazowska-Rutkowska B, Jakubiuk-Tomaszuk A, Cylwik B. Thyroid function in children with Down syndrome in the polish population: a case-control study. Arch Iran Med. 2020;23(6):386-390. doi: 10.34172/aim.2020.31.
\end{abstract}

Received: January 31, 2019, Accepted: January 21, 2020, ePublished: June 1, 2020

\section{Introduction}

Down syndrome is one of the most important human genetic disorders and occurs in one out of 600-700 newborns. ${ }^{1,2}$ The number of people with Down syndrome in Poland is estimated at about 60000 . This disease is caused by an extra copy of chromosome 21 , giving three types of chromosomal changes: simple trisomy 21 (in approximately $90 \%-95 \%$ of cases), translocation trisomy $(5 \%-10 \%)$ and mosaic trisomy $(2 \%-4 \%))^{1,2}$ Patients with Down syndrome are likely to have a variety of illnesses, including thyroid diseases, diabetes, depression, obsessive-compulsive disorder, hearing loss, atlantoaxial subluxation and Alzheimer's disease. ${ }^{3}$ Thyroid diseases have been reported to have a prevalence rate of 3\%-54\% and these increase in frequency with increasing age of the individuals. ${ }^{4}$ Thyroid dysfunction ranges from subclinical to overt hypothyroidism, and rarely hyperthyroidism. ${ }^{5}$ Patients with subclinical thyroid disease have few or no clinical symptoms of thyroid dysfunction and thus, laboratory diagnosis is needed.

The aim of this study was to compare the prevalence rate and pattern of thyroid function in children with Down syndrome with its prevalence in the general Polish population. The novelty of this work is that the study was conducted on Polish children and that the anti-thyroidstimulating hormone (TSH) receptor antibodies (TSHR) were investigated as an additional test in all children with Down syndrome. These antibodies are not evaluated routinely.

\section{Material and Methods \\ Study Subjects}

The study group consisted of 30 children (18 boys and 12 girls), aged 6-12 years (mean age: 7.8), with cytogenetically confirmed Down syndrome: simple trisomy $21(47, \mathrm{XY},+21$ or $47, \mathrm{XX},+21)$. These children reported clinical symptoms suggesting thyroid dysfunction (e.g. dry or cold skin, weight increase, intolerance to cold). The control group included 27 children (16 boys and 11 girls), also aged 6-12 years (mean age: 8.8 ) without signs of Down syndrome. To conduct this populationbased case-control study, data of all the children were 
retrieved from the database of the Department of Pediatric Neurology and Rehabilitation, Children's University Hospital in Bialystok. The cases and controls were taken from comparable populations, and the same exclusion criteria were used for both. They had negative history for thyroid diseases and autoimmune disorders, did not show side-effects of infection, and did not take any drugs for at least four weeks. Children with autoimmune disorders have specific antibodies in the serum that could interfere with determination of anti-TPO and anti-TG antibodies. Thyroid dysfunction was defined based on alterations in serum TSH, fT4, fT3 concentrations, anti-thyroid peroxidase antibodies (anti-TPO), anti-thyroglobulin (anti-TG) and anti-thyroid stimulating hormone receptor (anti-TSHR) antibodies. Subclinical hypothyroidism was defined as an elevated serum TSH concentration in association with serum normal total or free thyroxine (fT4) or triiodothyronine (T3) levels. In turn, overt hypothyroidism was defined as elevated serum TSH levels with decreased serum concentrations of T4 or T3. Baseline characteristics of the children with Down syndrome and controls are presented in Table 1. The study was approved by the Bioethics Committee, Medical University of Bialystok (R-I-002/484/2010). Written informed consent was obtained from parents or guardians after explaining the nature of the study to them.

\section{Blood Sampling}

Venous blood samples $(2 \mathrm{~mL})$ were taken once, in a fasting state, in the morning at the pediatric clinic. The blood was allowed to clot completely at room temperature, and was centrifuged to obtain the serum (centrifugation at $1.500 \mathrm{x}$ $\mathrm{g}$ for 5 minutes). The values of TSH, fT3, fT4, anti-TPO, anti-TG and anti-TSHR were determined on an ongoing basis.

\section{Laboratory Tests}

Serum TSH, fT4, free triiodothyronine (fT3), anti-TPO, anti-TG and anti-TSHR antibodies were determined by electrochemiluminescence method using the Elecsys TSH,
FT3 III, FT4 II, anti-TPO, anti-TG and anti-TSHR kits (Roche, Germany) on the Cobas e 411 immunoassay analyzer (Roche, Japan). In this technique, a mixture of streptavidin-and ruthenium-coated microparticles and specific antibodies are added to $10 \mu \mathrm{L}$ of patient's serum (containing target antigens). The established antigenantibody complex formed is immobilized on the surface of microparticles and washed out to remove unreacted components. Next, the complex is transferred to the measurement chamber where stage 2 of the reaction occurs, i.e. binding of microparticles to the electrode surface. In the subsequent stage, the electron tripropylamine donor is added and the application of voltage to the electrode induces chemiluminescence resulting in a continuous photon emission. The photons are measured with a photomultiplier, and the intensity of their emission is calculated by the program and converted into the concentration of the substance assessed. In children aged 6-12 years, the reference range of TSH has been estimated at $0.28-4.3 \mu \mathrm{IU} / \mathrm{mL}$, fT 4 at $1.1-1.7 \mathrm{ng} / \mathrm{dL}$ and $\mathrm{fT} 3$ at $2.7-5.2 \mathrm{pg} / \mathrm{mL}$, anti-TG at $0-115 \mathrm{IU} / \mathrm{mL}$, anti-TPO at 0-34 IU/mL and anti-TSHR 0-1.7 IU/L.

\section{Statistical Analysis}

All analyses were conducted using Statistica $12 \mathrm{PL}$ (StatSoft, Poland). Results were expressed as means and standard deviations. The differences between the study and control group were evaluated by the Student's $t$ test for unpaired samples. Significance was considered at $P<$ 0.05 . The odds ratio (OR) with $95 \%$ confidence intervals (CI) were used to compare the prevalence of thyroid dysfunction between the children with Down syndrome and controls. To calculate OR, we used a two-by-two frequency table. To assess an exact probability value for the relationship between the two proportions of the $2 \times$ 2 contingency table, Fisher exact test for small samples was used. Univariate and multivariate logistic regression analysis were performed to predict the risk of developing Down syndrome in children based on the observed patients' characteristics.

Table 1. Baseline Characteristics of the Children with Down Syndrome and Controls

\begin{tabular}{|c|c|c|}
\hline Characteristics & Down syndrome $(n=30)$ & Controls $(n=27)$ \\
\hline Age $($ mean $\pm S D)(y)$ & $7.8 \pm 2.12$, range: $6-12$ & $8.8 \pm 1.85$, range: $6-12$ \\
\hline $\operatorname{Sex}(n)(F / M)$ & $12 / 18$ & $11 / 16$ \\
\hline Thyroid dysfunction (Y/N) (\%) & $14 / 16(46.7 \% / 53.3 \%)$ & $4 / 23(14.8 \% / 85.2 \%)$ \\
\hline Subclinical hypothyroidism $(\mathrm{Y} / \mathrm{N})(\%)$ & $10 / 20(33.3 \% / 66.7 \%)$ & $4 / 23(14.8 \% / 85.2 \%)$ \\
\hline Evident hypothyroidism (Y/N) (\%) & $2 / 28(6.67 \% / 93.33 \%)$ & None \\
\hline Goitre & None & None \\
\hline Karyotype: trisomy 21 (n) (\%) & $100(100 \%)$ & None \\
\hline Autoimmune disorders (diabetes, coeliac disease, connective tissue diseases) & None & None \\
\hline Infections & None & None \\
\hline Drugs (last 4 weeks) & None & None \\
\hline
\end{tabular}




\section{Results}

Of the 30 patients with Down syndrome, 14 (46.7\%) children had abnormal thyroid profiles. The median age of the children with thyroid dysfunction was 6.75 (range 6-12) years. Mean TSH and fT4 concentrations in the children with Down syndrome were found to be significantly increased compared to the controls (4.30 $\pm 1.9 \mu \mathrm{IU} / \mathrm{mL}, 95 \% \mathrm{CI}: 3.55-5.04 \mu \mathrm{IU} / \mathrm{mL}$ vs. $3.10 \pm$ $1.47 \mu \mathrm{IU} / \mathrm{mL}, 95 \% \mathrm{CI}: 2.52-3.68 \mu \mathrm{IU} / \mathrm{mL}, P=0.013$, 95\% CI: $0.26-2.14$, and $1.33 \pm 0.23 \mathrm{ng} / \mathrm{dL}, 95 \% \mathrm{CI}$ : $1.25-1.42$ vs. $1.19 \pm 0.14 \mathrm{ng} / \mathrm{dL}, 95 \% \mathrm{CI}: 1.13-1.25$, $P=0.008,95 \%$ CI: 0.04-0.24, respectively) (Table 2). Although the fT 4 concentrations in Down syndrome were elevated, they were within the normal range. Univariate logistic regression showed that a rise in TSH by $1 \mu \mathrm{IU} / \mathrm{mL}$ or fT4 by $0.1 \mathrm{ng} / \mathrm{dL}$ increased the risk of Down syndrome approximately $1.5-$ fold (i.e. by half) $(P=0.019)$ and $1.6-$ fold $(P=0.014)$, respectively (Table 3$)$. Multivariate logistic regression revealed that the simultaneous rise in TSH by 1 $\mu \mathrm{IU} / \mathrm{mL}$ and $\mathrm{fT} 4$ by $0.1 \mathrm{ng} / \mathrm{dL}$, increased the risk of Down syndrome two-fold ( $P=0.004$ and $P=0.003$ ) (Table 4). Age and sex did not increase the risk of Down syndrome (Table 3). Mean fT3, anti-TPO, and anti-TSHR levels in the study group were within the reference range. In Down syndrome, the frequency of anti-TG results exceeding the upper level of the normal range $(115 \mathrm{IU} / \mathrm{mL})$ was only $6.7 \%$ (two patients). Taking into account all the results of thyroid hormones, subclinical hypothyroidism was recognized in 10 children (aged 6-11 years) with Down syndrome $(33.3 \%)$ (high TSH and normal fT4 and fT3 levels). Two children (aged 7 and 12 years) (6.67\%) had evident hypothyroidism (high TSH and low fT4). In the control group, subclinical hypothyroidism was diagnosed in four $(14.8 \%)$ children. Children with Down syndrome more frequently had thyroid dysfunction as compared to the healthy controls. The odds ratio was 5 , which means that thyroid dysfunction in children with Down syndrome is up to 5 times more likely to occur as compared to healthy subjects (OR 5.0, 95\% CI: 1.4-18.1). The OR was statistically significant $(P=0.01)$ (Table 5).

\section{Discussion}

The aim of this study was to analyze thyroid function in children with Down syndrome. The basic question is why we have to evaluate the thyroid function in these children. It is known that thyroid dysfunction is more often recognized in children and adults with Down syndrome in comparison with the general population. ${ }^{6}$ Clinical data clearly indicate a relationship between Down syndrome and thyroid dysfunction in children. ${ }^{5,7-9}$ There are several forms of this dysfunction, such as congenital, subclinical or autoimmune hypothyroidism, and sometimes hyperthyroidism. Subclinical hypothyroidism occurs most often, as observed in our research. In this condition,

Table 2. Thyroid Function Markers in the Sera of Children with Down Syndrome

\begin{tabular}{|c|c|c|c|c|c|c|}
\hline Group & $\mathrm{TSH}(\mu \mathrm{IU} / \mathrm{mL})$ & fT3 $(\mathrm{pg} / \mathrm{mL})$ & fT4 (ng/dL) & anti-TPO (IU/mL) & anti-TG (IU/mL) & anti-TSHR (IU/L) \\
\hline \multirow{2}{*}{$\begin{array}{l}\text { Controls } \\
(n=27)\end{array}$} & $3.10 \pm 1.47$ & $4.11 \pm 0.43$ & $1.19 \pm 0.14$ & $6.95 \pm 5.55$ & $13.60 \pm 4.18$ & $0.42 \pm 0.13$ \\
\hline & $95 \% \mathrm{Cl}: 2.52-3.68$ & $95 \% \mathrm{Cl}: 3.93-4.27$ & $95 \% \mathrm{Cl}: 1.13-1.25$ & $95 \% \mathrm{Cl}: 4.75-9.15$ & $95 \% \mathrm{Cl}: 11.94-15.25$ & $95 \% \mathrm{Cl}: 0.37-0.48$ \\
\hline \multirow{4}{*}{$\begin{array}{l}\text { Down } \\
\text { syndrome } \\
(n=30)\end{array}$} & $4.30 \pm 1.99$ & $3.98 \pm 0.40$ & $1.33 \pm 0.23$ & $7.74 \pm 5.28$ & $48.0 \pm 120$ & $0.48 \pm 0.22$ \\
\hline & $95 \%$ Cl: $3.55-5.04$ & $95 \%$ Cl: $3.83-4.13$ & $95 \%$ Cl: $1.25-1.42$ & $95 \%$ Cl: 5.77-9.71 & $95 \%$ Cl: $3.06-92.8$ & $95 \%$ Cl: $0.40-0.56$ \\
\hline & $P=0.013$ & $P=0.269$ & $P=0.008$ & $P=0.585$ & $P=0.144$ & $P=0.278$ \\
\hline & $95 \% \mathrm{Cl}: 0.26-2.14$ & $95 \% \mathrm{Cl}:-0.34-0.1$ & $95 \%$ Cl: $0.04-0.24$ & $95 \% \mathrm{Cl}:-2.09-3.66$ & $95 \% \mathrm{Cl}:-12.1-0.15$ & $95 \%$ Cl: $80.8-0.15$ \\
\hline
\end{tabular}

Data are means and standard deviations.

* Significant difference when compared to the control group $(P<0.05)$.

95\% Cl, 95\% confidence interval; TSH, thyroid-stimulating hormone; fT3, free triiodothyronine; fT4, free thyroxine; anti-TPO, anti-thyroid peroxidase antibodies; anti-TG, anti-thyroglobulin antibodies; anti-TSHR, anti-thyroid stimulating hormone receptor antibodies.

Table 3. Univariate Logistic Regression Analysis for the Variables Associated with Down Syndrome Progression in Children

\begin{tabular}{lllll}
\hline Variable & OR & SE & P value & 95\% Cl \\
\hline Age & 0.80 & 0.1096 & 0.099 & $0.61-1.04$ \\
Sex (boys) & 1.0 & 0.5575 & 0.955 & $0.36-2.97$ \\
TSH & 1.5 & 0.2643 & $0.019 *$ & $1.07-2.13$ \\
fT4 & 1.6 & 0.2832 & $0.014^{*}$ & 0.267 \\
fT3 & 0.48 & 0.3180 & 0.206 & $0.13-1.76$ \\
anti-TG & 1.03 & 0.0277 & 0.581 & $0.98-1.09$ \\
anti-TPO & 1.03 & 0.0535 & 0.278 & $0.93-1.14$ \\
anti-TSHR & 5.31 & 8.1786 & $0.26-109$ \\
\hline
\end{tabular}

OR, odds ratio; SE, standard error; 95\% Cl, 95\% confidence interval; TSH, thyroid-stimulating hormone; fT3, free triiodothyronine; fT4, free thyroxine; anti-TPO, anti-thyroid peroxidase antibodies; anti-TG, anti-thyroglobulin antibodies; anti-TSHR, anti-thyroid stimulating hormone receptor antibodies. 
Table 4. Multivariate Logistic Regression Analysis for the Variables Associated with Down Syndrome Progression in Children

\begin{tabular}{lllll}
\hline Variable & OR & SE & $\boldsymbol{P}$ value & $\mathbf{9 5 \% ~ C l}$ \\
\hline Age & 0.94 & 0.1509 & 0.699 & $0.68-1.29$ \\
TSH & 2.00 & 0.4814 & $0.004^{*}$ & $1.26-3.21$ \\
fT4 & 2.15 & 0.5441 & $0.003^{*}$ & $1.31-3.53$ \\
\hline
\end{tabular}

$\mathrm{OR}$, odds ratio; $\mathrm{SE}$, standard error; $95 \% \mathrm{Cl}$, 95\% confidence interval; $\mathrm{TSH}$, thyroid-stimulating hormone; fT4, free thyroxine.

Table 5. The Prevalence of the Thyroid Dysfunction in Children with Down Syndrome

\begin{tabular}{lcc}
\hline Characteristics & Down syndrome $(\mathbf{n}=\mathbf{3 0})$ & Controls $(\mathbf{n}=\mathbf{2 7})$ \\
\hline Thyroid dysfunction & & \\
Yes & 14 & 4 \\
No & 16 & 23 \\
Odds ratio $(95 \% \mathrm{Cl})$ & $5.0(1.4-18.1)$ & - \\
$P$ value & 0.01 & - \\
\hline
\end{tabular}

elevated serum TSH concentrations with normal thyroxine (T4) and T3 levels are observed. There are several causes for subclinical hypothyroidism in children with Down syndrome, but the mechanism is not completely known yet.

One theory is that the hyper-responsiveness to interferon caused by over-expression of the genes that encode the interferon receptors could be the cause of hypothyroidism in Down syndrome. ${ }^{8}$ According to some authors, under in-vivo conditions, treatment with interferon alpha can cause thyroiditis by immune modulatory mechanisms and a direct thyroid toxic effect. ${ }^{10,11}$ In turn, under invitro conditions, interferon 1 down regulates the gene expression of protein taking part in T4 hormone synthesis and secretion. ${ }^{10}$

Another theory suggests thyroid autoimmunity. A few authors have reported positivity of thyroid peroxidase (TPO) antibody in children suffering from subclinical hypothyroidism..$^{6,8,12-14}$ Its prevalence in Down syndrome patients has been found to be $7.5 \%, 27 \%$ and $31 \% .^{13,15-}$ ${ }^{17}$ It is believed that TPO occurs later in childhood, increasing with age, and is more common after the age of 8 years. ${ }^{4,5}$ However, TPO antibodies were found in infants with Down syndrome. ${ }^{8}$ Pascanu et al observed that in children with Down syndrome over 5 years of age and TSH concentration above $11 \mathrm{mU} / \mathrm{L}$, the anti-TPO levels were elevated. ${ }^{8}$ In our study, all concentrations of anti-TPO were considered normal. Taking into account other autoantibodies, positive anti-TG antibodies were detected in only two children (6.7\%), and anti-TSHR antibodies were negative in all tested patients. Faria et al showed positive thyroid antibodies in $16 \%$ patients in a long-term period ranging from 8 to 28 months of observation. ${ }^{18}$ The autoantibodies appear long before the clinical manifestations of autoimmune disease. Many authors have observed higher prevalence of autoimmune type disease in Down syndrome patients, including hypothyroidism, Hashimoto's thyroidism, congenital hypothyroidism and Graves' disease. ${ }^{19}$ According to some authors, thyroid function should be controlled in patients who simultaneously have subclinical hypothyroidism and positivity of TPO antibody. ${ }^{12}$ Other factors leading to subclinical hypothyroidism include the hypothalamicpituitary-thyroid axis immaturity, which is a self-limiting autoimmune process, an impaired release of TSH because of central disorders or incorrect dopaminergic regulation of the pituitary. ${ }^{12,18,20}$ Among the different hypotheses leading to subclinical hypothyroidism, especially in the first years of life of Down syndrome children, there is a local peripheral disorder in T3 production or activity, thyroid insensitivity to TSH, abnormal secretion, or TSH with reduced activity at the central level. ${ }^{12,21,22}$

In our study, thyroid dysfunction in Down syndrome was defined based on laboratory tests, such as alterations in serum TSH, fT4, fT3 concentrations and anti-TPO, anti-TG and anti-TSHR antibodies. We found an abnormal thyroid profile, mainly indicating subclinical hypothyroidism, in almost half of these children. Most of them had an intermittent isolated increase in TSH and the value of $\mathrm{fT} 3$ remained normal. In contrast, median fT4 concentration in children with Down syndrome was elevated, but it was within the normal range. Anti-TPO and anti-TG antibodies were not detected. The results of our study are consistent with literature data. Tuysuz and Beker showed that the incidence of hypothyroidism was $28.1 \%$ in pediatric patients suffering from Down syndrome aged 5 days to 10 years, and half of them were subclinical in nature. Their T4 concentrations were observed to be normal or near the lower limit of normal. ${ }^{20}$ Jimenez-Lopez et al found subclinical hypothyroidism in $45.8 \%$ of children with Down syndrome ( 1 month to 6 years old). ${ }^{23}$ In their research, only $14 \%$ of the control children had elevated levels of TSH, which is almost the same as our findings. Patients with subclinical thyroid disease had no clinical symptoms. It seems that in such conditions laboratory diagnosis is needed. Therefore, we postulate that each patient with Down syndrome should be screened for thyroid disease. Similarly, some authors propose laboratory tests every 3 months in children with subclinical hypothyroidism and once a year in children with normal thyroid function. ${ }^{8,20}$ Knowing the results of laboratory tests, the patient's treatment may or may not be administered. A number of elements are in favor of subclinical hypothyroidism therapy, e.g. lack of adverse side effects or benefits of normal child development. ${ }^{4,6,8,20,22}$ Other authors recommend not treating subclinical hypothyroidism, for example due to only transient TSH elevation. ${ }^{8,12}$ The discussion is still open whether subclinical hypothyroidism requires treatment.

We concluded that children with Down syndrome 
might have increased secretion of TSH, even when thyroid hormone and autoantibodies are normal. The results of this study suggest that an isolated increase in TSH in Down syndrome does not predispose the patient to the development of thyroid disease. We also suggest that all patients with Down syndrome should be screened for thyroid dysgenesis, as they have thyroid dysfunction more frequently compared to the general healthy population. Due to the large number of factors that influence baseline thyroid hormone and endogenous TSH concentrations, only simultaneous application of TSH and fT 4 screening tests may help fully assess the functional status of the thyroid. We postulate that subclinical hypothyroidism is a common comorbidity in the first years of life of children suffering from Down syndrome.

\section{Authors' Contribution}

BZR contributed to research concept and study design, performance of the tests, statistical analysis, data analysis and interpretation, drafting the article. AJT contributed to recruitment of the participants, clinical examination, sample collection, and data acquisition, clinical assessment and consulting. BC contributed to research concept, data analysis and interpretation, substantial supervision and coordination of the study, editing and reviewing the manuscript.

\section{Conflict of Interest Disclosures}

The authors have no conflicts of interest.

\section{Ethical Statement}

The study was approved by the Bioethics Committee, Medical University of Bialystok (R-I-002/484/2010).

\section{References}

1. Mazurek D, Wyka J. Down syndrome-genetic and nutritional aspects of accompanying disorders. Rocz Panstw Zakl Hig. 2015;66:189-94.

2. Mikkelsen M. Down syndrome: cytogenetical epidemiology. Hereditas. 1977;86:45-50. doi:10.1111/j.1601-5223.1977. tb01211.x.

3. Asim A, Kumar A, Muthuswamy S, Jain S, Agarwal S. Down syndrome: an insight of the disease. J Biomed Sci. 2015;22:4145. doi: 10.1186/s12929-015-0138-y.

4. Karlsson B, Gustafsson J, Hedov G, Ivarsson S, Anneren G. Thyroid dysfunction in Down syndrome: related to age and thyroid autoimmunity. Arch Dis Child. 1998;79:242-5. doi: 10.1136/adc.79.3.242.

5. King K, O'Gorman C, Gallagher S. Thyroid dysfunction in children with Down syndrome: a literature review. Ir J Med Sci. 2014;183:1-6. doi: 10.1007/s11845-013-0994-y.

6. Prasher VP. Down syndrome and thyroid disorders - a review. Downs Syndr Res Pract. 1999;6:25-42. doi: 10.3104/ reviews.95.

7. Cutler AT, Benezra-Obeiter R, Brink SJ. Thyroid function in young children with Down syndrome. Am J Dis Child. 1986;140:47983. doi: 10.1001/ archpedi.1986.02140190089034.

8. Pascanu I, Banescu C, Benedek T, Duicu C, Csep K, Dema A. Thyroid dysfunction in children with Down's Syndrome. Acta
Endocrinol. 2009;5:85-92.

9. Pueschel SM, Pezzullo JC. Thyroid dysfunction in Down syndrome. Am J Dis Child. 1985;139:636-9. doi: 10.1001/ archpedi.1985.02140080106045.

10. Caraccio N. Dardano A. Manfredonia F, Manca L, Pasquali L, ludice $A$, et al. Long-term follow-up of 106 multiple sclerosis patients undergoing interferon-beta $1 \mathrm{a}$ or $1 \mathrm{~b}$ therapy: predictive factors of thyroid disease development and duration. J Clin Endocrinol Metab. 2005;90:4133-7. doi: 10.1210/jc.2004-2326.

11. Tomer $\mathrm{Y}$, Blackard JT, Akeno N. Interferon alpha treatment and thyroid dysfunction. Endocrinol Metab Clin North Am. 2007;36:1051-66. doi: 10.1016/j.ecl.2007.07.001.

12. Gibson PA, Newton RW, Selby K, Price DA, Leyland K, Addison GM. Longitudinal study of thyroid function in Down's syndrome in the first two decades. Arch Dis Child. 2005;90:574-8. doi: 10.1136/adc.2004.049536.

13. Rashid N, Mumtaz A, Mehmood S, Afzal N, Haq S, Ahmad T. Assessment of thyroid dysfunction in Down syndrome patients. Pak Paediatr J. 2009;33:211-217.

14. Rubello D, Pozzan GB, Casara D, Girelii ME, Boccato S, Rigon F, et al. Natural course of subclinical hypothyroidism in Down's syndrome: prospective study results and therapeutic considerations. J Endocrinol Invest. 1995;18:35-40. doi: 10.1007/BF03349694.

15. Ivarsson SA, Ericsson UB, Gustafsson J, Forslund M, Vegfors $P$, Anneren G. The impact of thyroid autoimmunity in children and adolescents with Down syndrome. Acta Paediatr. 1997;86:1065-7. doi: 10.1111/j.1651-2227.1997.tb14808.x.

16. Loudon MM, Day RE, Duke EM. Thyroid dysfunction in Down's syndrome. Arch Dis Child. 1985;60:1149-51. doi: 10.1136/adc.60.12.1149.

17. Noble SE, Leyland K, Findlay CA, Clark CE, Redfern J, Mackenzie JM, et al. School based screening for hypothyroidism in Down's syndrome by dried blood spot TSH measurement. Arch Dis Child. 2000;82:27-31. doi: 10.1136/ adc.82.1.27.

18. Faria CD, Ribeiro S, Kochi C, Silva AP, Ribeiro BN, Marcal LT, et al. TSH neurosecretory dysfunction (TSH-nd) in Down syndrome (DS): low risk of progression to Hashimoto's thyroiditis. Arq Bras Endocrinol Metabol. 2011;55:628-31. doi: $\quad 10.1590 / \mathrm{s} 0004-27302011000800018$.

19. Nebesio TD, Eugster EA. Unusual thyroid constellation in Down syndrome: congenital hypothyroidism, Graves' disease, and hemiagenesis in the same child. J Pediatr Endocrinol Metab. 2009;22:263-8. doi: 10.1515/jpem.2009.22.3.263.

20. Tuysuz B, Beker DB. Thyroid dysfunction in children with Down's syndrome. Acta Paediatr. 2001;90:1389-93. doi: 10.1080/08035250152708770.

21. Selikowitz M: A five-year longitudinal study of thyroid function in children with Down syndrome. Dev Med Child Neurol. 1993;35:396-401. doi: 10.1111/j.1469-8749.1993. tb11660.x.

22. Sharav T, Collins RM, Baab PJ. Growth studies in infants and children with Down's syndrome and elevated levels of thyrotropin. Am J Dis Child. 1988;142:1302-6. doi: 10.1001/ archpedi.1988.02150120056040.

23. Jimenez-Lopez V, Arias A, Arata-Bellabarba G, Vivas E, Delgado MC, Paoli M. Concentration of thyrotropic hormone and free thyroxin in children with Down's syndrome. Invest Clin. 2001;42:123-130. 